\title{
Probabilistic analysis of drought spatiotemporal characteristics in Thessaly region, Greece
}

\author{
A. Loukas ${ }^{1}$ and L. Vasiliades ${ }^{2}$ \\ ${ }^{1}$ Department of Civil Engineering, University of Thessaly, Greece \\ ${ }^{2}$ Department of Management of Environment and Natural Resources, University of Thessaly, Greece
}

Received: 4 August 2004 - Revised: 14 October 2004 - Accepted: 16 October 2004 - Published: 17 November 2004

\begin{abstract}
The temporal and spatial characteristics of meteorological drought are investigated to provide a framework for sustainable water resources management in the region of Thessaly, Greece. Thessaly is the most intensely cultivated and productive agricultural plain region in Greece. Thessaly's total area is about $13700 \mathrm{~km}^{2}$ and it is surrounded by mountains and traversed by Pinios River. Using the Standardized Precipitation Index (SPI) as an indicator of drought severity, the characteristics of droughts are examined. Thessaly was divided into 212 grid-cells of $8 \times 8 \mathrm{~km}$ and monthly precipitation data for the period 1960-1993 from 50 meteorological stations were used for global interpolation of precipitation using spatial co-ordinates and elevation data. Drought severity was assessed from the estimated gridded SPI values at multiple time scales. Firstly, the temporal and spatial characteristics of droughts were analyzed and then, Drought Severity - Areal extent - Frequency (SAF) annual and monthly curves were developed. The analysis indicated that moderate and severe droughts are common in Thessaly region. Using the SAF curves, the return period of selected severe drought events was assessed.
\end{abstract}

\section{Introduction}

Droughts are long-term phenomena affecting large regions causing significant damages both in human lives and economic losses. Droughts are the costliest natural disaster of the world and affect more people than any other natural disaster (Wilhite, 2000). Droughts are generally considered as periods with insufficient precipitation, soil moisture and water resources for sustaining and supplying the socio-economic activities of a region. There is not, however, a universal definition of drought due to the wide variety of sectors affected by drought, its diverse geographical and temporal distribution and the demand placed on water supply by human-use

Correspondence to: A. Loukas

(aloukas@uth.gr) systems. The most well-known and widely used classification of droughts is the classification initially proposed by Dracup and his associates (1980) and integrated later by Wilhite and Glantz (1985). The American Meteorological Society (2004) adopted this drought classification system. Based on the nature of the water deficit, four types of droughts are defined: a) the meteorological drought which is defined as a lack of precipitation over region for a period of time, b) the hydrological drought which is related to a period with inadequate surface and subsurface water resources to supply established water uses of a given water resources management system, c) the agricultural drought, which, usually, refers to a period with declining soil moisture and consequent crop failure without any reference to surface water resources, d) the socio-economic drought which is associated to the failure of water resources systems to meet the water demands and thus, associating droughts with supply of and demand for an economic good (water). The first three categories are referred as environmental droughts, and the socio-economic drought is considered as water resources systems droughts (Wilhite, 2000).

It is necessary, for the analysis of droughts, to detect several drought features such as the onset and end time of drought, drought duration, drought areal extent, drought severity, drought frequency, and to link the drought variability to climate (Piechota and Dracup, 1996). Numerous specialized indices have been proposed to quantify the four types of drought events. However, many indices are used for the identification of more than one type of drought (Tate and Gustard, 2000; Keyantash and Dracup, 2002) and their categorization may not be appropriate, although it is widely used.

The most commonly used meteorological drought indices are: 1) Discrete and cumulative precipitation anomalies, 2) the Z-score or Standardized Rainfall Anomalies (Jones and Hulme, 1996), 3) Rainfall deciles (Gibbs and Maher, 1967), 4) the Palmer Drought Severity Index (PDSI) (Palmer, 1965), 5) the Bhalme - Mooley Drought Index (BMDI) (Bhalme and Mooley, 1980), 6) the Rainfall Anomaly Index (RAI) 


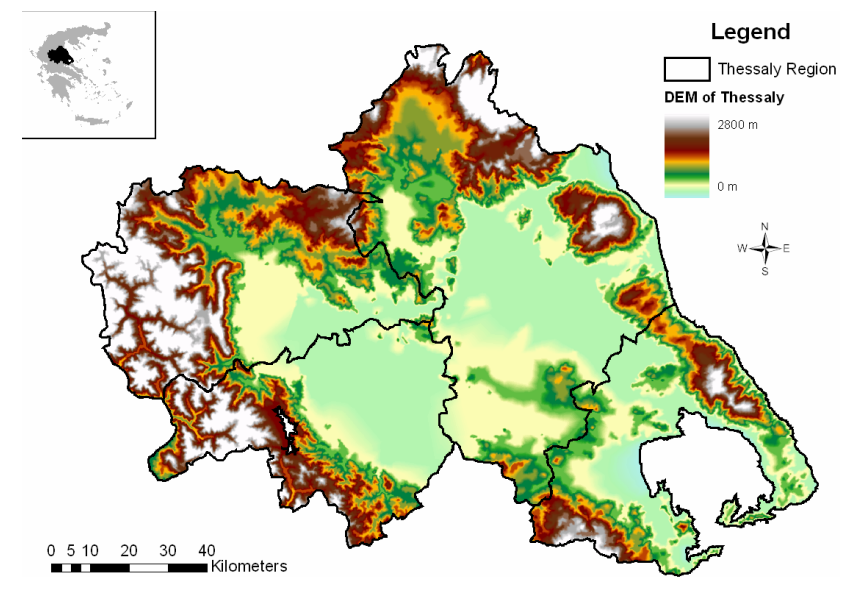

Fig. 1. Digital elevation model of Thessaly region.

(van Rooy, 1965), and 7) the Standardized Precipitation Index (SPI) (McKee et al., 1993). The Standardized Precipitation Index quantifies the precipitation deficit for multiple time scales and reflects the impact of drought on the availability of different types of water resources. For example, the moisture stored in the soil is highly affected by the shortterm precipitation anomalies, whereas streamflow, groundwater and reservoir storage slowly respond to longer-term precipitation anomalies. Wetter and drier climates can be represented in the same way by SPI, because it is a normalized index.

A large number of studies on testing the effectiveness of the various indices for the detection and monitoring of drought events and regional drought analyses could be found in the international literature. A spectral analysis (Guttman, 1998) comparing historical time series of PDSI with time series of SPI revealed that the spectral characteristics of the SPI are spatially invariant while those of PDSI are spatially variable and for this reason the SPI is a better drought index for interregional comparison of drought events. Guttman (1998) also found that the 12-month SPI oscillations were found to be in phase with the oscillations of PDSI. Similar results were found in an intercomparison of SPI, Zscore, RAI, the PDSI and the Palmer moisture anomaly index (Z-Index) (Palmer, 1965) at 28 meteorological stations in Greece (Loukas et al., 2003). In that study, the oscillations of the SPI were found to be in phase with the oscillations of the Z-score and the RAI for the same time-scales and with the oscillations of the PDSI for time-scales larger than 6-months. Gonzalez and Valdes (2004) proposed a new methodology to compute the Mean Frequency of Recurrence (MFR) of droughts and compared the results of their methodology with PDSI and SPI for Texas and Gibraltar. They concluded that the main advantage of MFR calculation procedure over SPI is that the proposed procedure allows the comparison of drought events that, even when they correspond to the same time-scale, have different durations. Furthermore, Gonzalez and Valdes confirmed the findings of Guttman (1998) presented above. Hayes and his associates (1999) used the SPI for the monitoring of the 1996 drought in the southern and southwestern USA and they demonstrated that the SPI has the ability to detect the onset of the drought and monitor its progression. By comparing the SPI with the PDSI, they concluded that the SPI detected the onset of the 1996 drought at least one month earlier than the PDSI.

The meteorological drought indices were used for the estimation and assessment of soil moisture and the prognosis of agricultural production. In a case study for North Carolina (Sims et al., 2002), the SPI and the PDSI were used for estimating soil moisture. The results suggested that the SPI is more representative of short-term precipitation than the PDSI and thus a better indicator for soil moisture variation and soil wetness. The soil moisture is the main indicator of agricultural drought and affects the agricultural production. Quiring and Papakryiakou (2003) evaluated the effectiveness of the SPI, the PDSI, the Palmer Z-Index, and the NOAA Drought Index for identification of agricultural drought for the Canadian prairies. Their analysis showed that the Z-Index and the SPI better represent the moisture state of the soil and thus, these indices are better predictors of the crop production.

Recently, several studies analyzed the relationship between droughts and climatic indicators and the teleconnections of droughts and climate variability over large areas. Piechota and Dracup (1996) investigated the hydroclimatic response in the USA to extreme phases of the Southern Oscillation. They found a strong relationship between El Niño and extreme drought years in the Pacific Northwest and in southern United States, where dry conditions occur consistently during La Niña events. Another study (Chiew et al., 1998) showed that the occurrence of droughts in Australia is closely associated with El Niño events. Furthermore, in a recent study at Nebraska, USA (Tadesse et al., 2004) drought indices (SPI and PDSI) were linked with oceanic indices using data mining techniques for drought monitoring. Hoerling and Kumar (2003) analyzed the 1998-2002 droughts affected the United States, southern Europe, and Southwest Asia and they found that this prolonged and widespread drought event was linked to a common oceanic influence. During that period, the Cold Sea Surface Temperatures (SSTs) in the eastern tropical Pacific Ocean and the warm SSTs in the western tropical Pacific and Indian oceans were remarkably persistent, contributing to synchronized and spatially expansive mid-latitude droughts. Analysis of the SPI over the Northern Hemisphere (Bordi and Sutera, 2001) revealed that the dry conditions over Europe, eastern Asia, central Africa and the Caribbean region are interconnected and affected by the tropical climatic variability.

The SPI was used in recent regional drought analyses in the Mediterranean region using rain gauge data (Bordi et al., 2001; Lana et al., 2001), gridded rain gauge data (Lloyd-Hughes and Saunders, 2002; Tsakiris and Vangelis, 2004), and NCEP/NCAR reanalysis gridded precipitation data (Bordi and Sutera, 2001). The above studies indicate that the Mediterranean region has been affected by severe and more or less prolonged periods of drought in the last 50 years. 


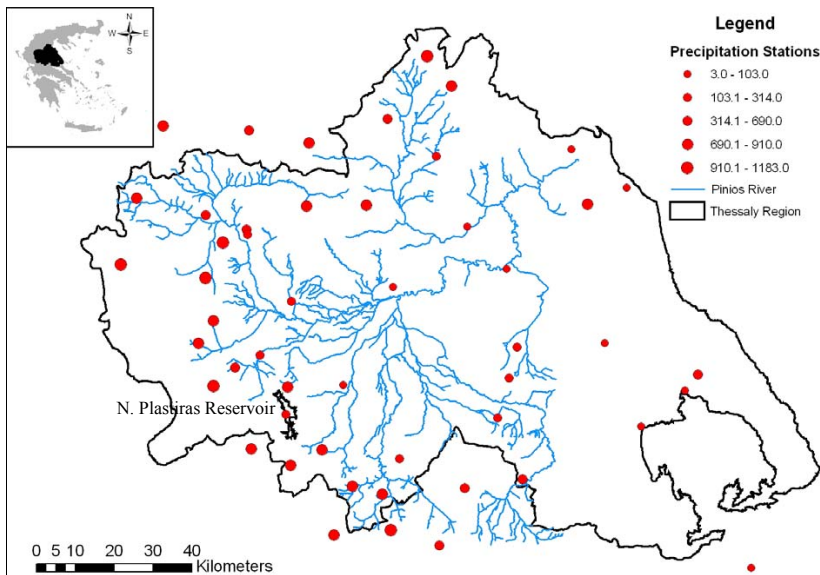

Fig. 2. Location and elevation of the precipitation stations used in this study.

In this study, the drought was considered as a meteorological phenomenon characterized by prolonged periods of abnormal precipitation deficit. The SPI was used for the identification and the assessment of drought events. The use of SPI for the detection of drought at multiple time-scales is well documented (McKee et al., 1995; Guttman, 1999) and presented earlier in the paper. The observed monthly precipitation data from 50 gauges for 33 hydrological years were spatially distributed into 212 grids of $8 \times 8 \mathrm{~km}$ using a global interpolation technique. The precipitation grid data were, then, used for the estimation of the SPI time series. A practical method for developing annual and monthly Drought Intensity or Drought Severity-Areal Extent-Frequency (SAF) curves is proposed. This methodology provides useful information to characterize a regional drought event and to plan the water resources management in semi-arid regions. The methodology was applied to Thessaly region of Greece.

\section{The Thessaly region and database}

The study area is the Thessaly region located in Greece (Fig. 1). Thessaly is a plain region surrounded by Mount Kisavos and Mount Pelion in the east, along the coast of the Aegean Sea, Mount Olympus in the north, the Pindus Mountain Range in the west, and the Othrys Mountain Range in the south. Thessaly's total area is about $13700 \mathrm{~km}^{2}$. The elevation ranges from sea level at the eastern coastal area to more than $2800 \mathrm{~m}$ at the eastern and western mountain areas, and the mean elevation of the region is nearly $500 \mathrm{~m}$ (Fig. 1).

At the western side of Thessaly the climate is continental; the winters are cold and the summers are hot and the temperature difference between the two seasons is large. At the eastern side of Thessaly the climate is typical Mediterranean climate. Summers in Thessaly are usually very hot and dry, and in July and August temperatures can reach 40 ${ }^{\circ} \mathrm{C}$. Mean annual precipitation over the whole Thessaly region is about $700 \mathrm{~mm}$ and it is distributed unevenly in space

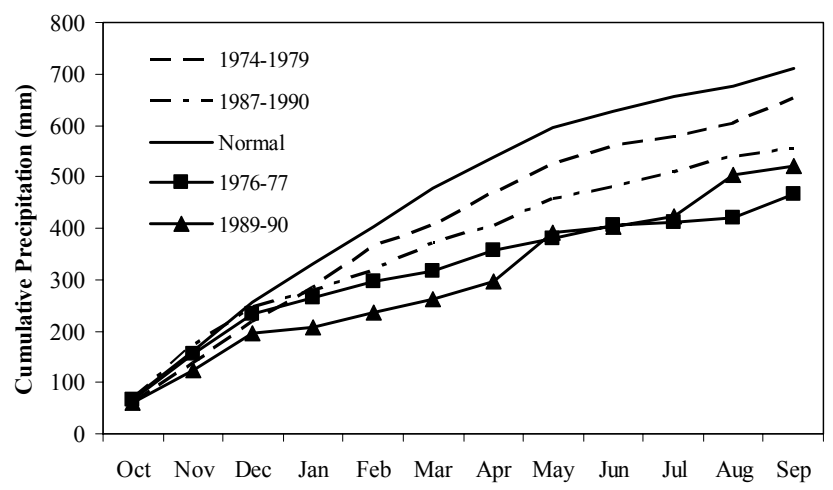

Fig. 3. Cumulative areal precipitation for selected dry years and periods.

and time. The mean annual precipitation varies from about $400 \mathrm{~mm}$ at the central plain area to more than $1850 \mathrm{~mm}$ at the western mountain peaks. Generally, rainfall is rare from June to August. The mountain areas receive significant amounts of snow during the winter months and transient snowpacks develop.

Thessaly plain is the most productive agricultural region of Greece with an area of about $4000 \mathrm{~km}^{2}$ (Fig. 1). The main crops cultivated in the plain area are cotton, wheat and maize whereas apple, apricot, cherry, olive trees and grapes are cultivated at the foothills of the eastern mountains. Pinios River and its tributaries traverse the plain area, and the basin total drainage area is about $9500 \mathrm{~km}^{2}$ (Fig. 2). The waters of Pinios River are used primarily for irrigation and for use in hydroelectric power plant located at Smokovo. The intense and extensive cultivation of water demanding crops has lead to a remarkable water demand increase, which is usually fulfilled by the over-exploitation of groundwater resources. For example, nearly 65000 ha are irrigated with surface waters and more than 210000 ha of agricultural area are supplied by groundwater. The overexploitation of the groundwater, especially during extended dry periods, has lead to the deterioration of the already disturbed water balance and the degradation of water resources. Over the years, various locations within Pinios River basin have been proposed for the development of reservoirs, but only the dam of Smokovo has been recently constructed. The only other surface water developments in Thessaly region are a few small reservoirs and lagoons on or adjacent to Pinios River and the diversion of water from the N. Plastiras reservoir (Fig. 2), which is located outside of the Pinios River basin (Loukas and Mylopoulos, 2004).

Thessaly experienced severe, extreme and persistent droughts during the period from mid to late 1970s and the period from late 1980s to early 1990s. The average cumulative areal precipitation during these two periods is compared to normal cumulative areal precipitation in Fig. 3. During these two periods the monthly and annual precipitation was significantly bellow normal. Especially, the hydrological years 1976-1977 and 1989-1990 are the first and second driest hy- 
drological years in record, respectively (Fig. 3). The driest January and February and the second driest March in record occurred during the hydrological year 1989-1990. The prolonged and significant decrease of monthly and annual precipitation has a dramatic impact on water resources of the region. Usually, the dry periods are accompanied with high temperatures, which lead to higher evapotranspiration rates and dry soils. These conditions inversely affect both the natural vegetation and the agriculture of the region as well as the available storage of the reservoirs. Severe and extremely dry conditions result in irrigation cutbacks, overexploitation of groundwater and significant losses of crop yields. For example, during the dry hydrological year 1989-1990, the water supply for irrigation from the N. Plastiras reservoir was cutoff by more than $70 \%$ and the irrigated areas with surface water resources were reduced by $90 \%$.

The estimation of the SPI values was based on monthly precipitation data. Monthly precipitation data from 50 stations distributed over the Thessaly region (Fig. 2) and for the period October 1960 to September 1993 were available. The locations of the stations are shown in Fig. 2. The elevation of these stations ranges from $3 \mathrm{~m}$ to $1183 \mathrm{~m}$ (Fig. 2). These precipitation data were used for the spatial distribution of monthly precipitation over the Thessaly region as discussed in the next section of the paper.

\section{Methodology}

The methodology presented in this paper and applied to Thessaly region consisted of the spatial interpolation of precipitation gauge data and the generation of gridded precipitation data, the calculation of the SPI values for each grid using the respective gridded precipitation for multiple timescales, analysis of the temporal characteristics of droughts in the Thessaly region followed by the analysis of spatial characteristics of droughts in the Thessaly region and the development of Drought Severity-Areal Extent-Frequency curves for the region for monthly and mean annual droughts and multiple time-scales. The steps followed in the methodology are:

1. Interpolate the monthly precipitation measured at 50 stations for 33 hydrological years and create gridded monthly precipitation.

2. Calculate the time series of precipitation at various time scales (i.e. 1-month, 3-month, 6-month, 9-month, and 12-month) in each grid.

3. Estimate the mean areal precipitation of Thessaly for the various time scales from the time series of gridded precipitation calculated in step 2 .

4. Calculate the gridded SPI for the various time scales from the gridded precipitation time series of step 2 .

5. Calculate the regional representative SPI time series from the mean areal precipitation estimated in step 3.
These SPI time series were used for the temporal analysis of droughts.

6. Perform frequency analysis on the annual minimum values of regional representative SPI calculated in step 5.

7. Calculate the time series of the weighted annual cumulative drought severity and the annual average drought severity in each grid.

8. Enter the gridded values of SPI time series of various time scales and the time series of weighted annual cumulative drought severity and the annual average drought severity in a Geographical Information System (GIS) database.

9. Perform spatial analysis and visualize the drought severity for various time-scales and specific drought episodes in GIS.

10. Estimate the areas affected by specified drought severities using multiple queries in GIS.

11. Perform frequency analysis for each areal extent and the associated drought severity using the results of step 10 .

12. Develop the annual and monthly Drought Severity Areal Extent - Frequency (SAF) curves using the results of step 11.

In this study, the Geographical Information System was used for its ability to produce maps showing the spatial distribution of SPI and, once the maps are produced, to answer to multiple queries about the areas (or grids) having a specified value or a range of values of SPI. This ability is based on the connection of GIS with the developed database of SPI.

\subsection{Spatial interpolation of precipitation}

The spatial interpolation of precipitation over the Thessaly region was estimate by a simple Multiple Linear Regression (MLR) model proposed by Naoum and Tsanis (2003). The general form of the model is:

$$
\begin{aligned}
P= & a+b_{1} \cdot X+b_{2} \cdot Y+b_{3} \cdot Z+b_{4} \cdot X^{2} \\
& +b_{5} \cdot Y^{2}+b_{6} \cdot Z^{2}+b_{7} \cdot X \cdot Y+b_{8} \cdot X \cdot Z+b_{9} \cdot Y \cdot Z,
\end{aligned}
$$

where $P$ is the precipitation $(\mathrm{mm}), X$ is the longitude $(\mathrm{km})$, $Y$ is the latitude $(\mathrm{km}), Z$ is the elevation $(\mathrm{m})$.

This MLR model (Eq. 1) was developed using stepwise linear regression. Terms of higher order, only marginally improve the precipitation interpolation accuracy, leading, however, to spurious correlation between the interpolated and observed precipitation.

This MLR model was used because: i) it yields realistic spatial distribution of precipitation, ii) it provides reasonable estimates of areal precipitation for different scales, iii) it is not greatly influenced by the number and the spatial distribution of precipitation gauges when estimating mean areal precipitation and its spatial distribution, and iv) it is simple 
to apply. This model has been applied in Crete (Naoum and Tsanis, 2003) for annual precipitation and its results were comparable with other spatial interpolation methods (like splines, ordinary kriging, inverse distance weighting, and trend surface). Furthermore, in a recent study (Loukas et al., 2004), this MLR model was applied for the spatial interpolation of monthly and annual precipitation in the Pinios River basin, and its results were comparable to the results obtained by more sophisticated methods, like global methods (e.g. artificial neural networks and generalized artificial neural networks), local deterministic methods (e.g. inverse distance weighting and thin plate splines), geostatistical methods (e.g. ordinary kriging and universal kriging), and combinational methods (e.g. residual ordinary kriging and residual inverse distance weighting). The results of all spatial interpolation methods were both cross-validated and independently validated and have been shown that the simple MLR model gives reasonably good estimates of precipitation spatial distribution.

The MLR model was firstly calibrated using the monthly precipitation data from the 50 stations and its constants $(a$, $\left.b_{1}, b_{2}, \ldots, b_{9}\right)$ were estimated for each month of the period October 1960 to September 1993. This means that 396 monthly MLR models were developed. The monthly MLR models were consistent and the correlation between the predicted and observed annual precipitation was ranged from 0.79 to 0.92 . The developed MLR models gave better results for the wet winter months than the dry summer months. This is expected due to the large spatial variation of precipitation during summer.

The MLR models were then applied to estimate the precipitation in grid cells with dimensions of $8 \times 8 \mathrm{~km}$ and generate gridded precipitation for the period of October 1960 to September 1993. The total area of Thessaly was divided into 212 grids and their elevation was ranged from $45 \mathrm{~m}$ to $2060 \mathrm{~m}$. Although these are large grids, they are suitable for drought analysis since droughts are regional phenomena affecting large areas. Furthermore, the work presented in this paper is part of an ongoing research program. An objective of this research program is also to evaluate the forecasting potential of drought using, among others, remote sensing data, such as satellite vegetation indices (e.g. NDVI, VCI, etc.). Such remote sensing data are available, for the period of analysis, for grids $8 \times 8 \mathrm{~km}$, leading us to this selection of grid size.

\subsection{The Standardized Precipitation Index (SPI)}

The Standardized Precipitation Index (SPI) was developed for the purpose of defining and monitoring drought (McKee et al., 1993). Among others, the U.S. Colorado Climate Center, the U.S. Western Regional Climate Center, and the U.S. National Drought Mitigation Center use the SPI to monitor current states of drought in the United States. The SPI can track drought on multiple time-scales. The U.S. National Drought Mitigation Center computes the SPI with five running time intervals, i.e. 1-, 3-, 6-, 9-, and 12-months, but the index is flexible with respect to the period chosen. This powerful feature can provide an overwhelming amount of information unless researchers have a clear idea of the desired intervals. Furthermore, the U.S. National Drought Mitigation Center and the U.S. Western Regional Climate Center advocate SPI over the traditional PDSI (Redmond, 2000).

Computation of the SPI involves fitting a Gamma probability density function to a given frequency distribution of precipitation totals for a station. The alpha and beta parameters of the Gamma probability density function are estimated for each station, for each time scale of interest $(1,3,6,9,12$ months, etc.), and for each month of the year. The Gamma distribution is defined by its frequency or probability density function:

$g(P)=\frac{1}{\beta^{\alpha} \Gamma(\alpha)} P^{\alpha-1} e^{-P / \beta}$ for $\quad P>0$,

where $\alpha, \beta$ are the shape and scale parameters respectively, $P$ is the precipitation amount and $\Gamma(\alpha)$ is the gamma function. Maximum likelihood solutions are used to optimally estimate $\alpha$ and $\beta$ :

$\alpha=\frac{1}{4 A}\left(1+\sqrt{1+\frac{4 A}{3}}\right), \quad \beta=\frac{\bar{P}}{\alpha}$,

where $\mathrm{A}=\ln (\bar{P})-\frac{\sum \ln (P)}{n}$, and $n$ is the number of observations.

The resulting parameters are then used to find the cumulative probability of an observed precipitation event for the given month and time scale for the station in question. Since $g(P)$ is undefined for $P=0$ and a precipitation distribution may contain zeros, the cumulative probability becomes:

$H(P)=q+(1-q) G(P)$,

where $q$ is the probability of a zero and $G(P)$ the cumulative probability of the incomplete gamma function. If $m$ is the number of zeros in a precipitation time series, then $q$ can be estimated by $m / n$. By applying Eq. (3), errors are eventually introduced to parameters $\alpha$ and $\beta$ of Gamma distribution. These errors depend on the number of months with null precipitation $(P=0)$ and they are evident only for the 1-month precipitation. In this study, the time series of monthly precipitation had only two cases of zero precipitation, observed during July and August. For larger time scales (e.g. 3-month, 6-month, etc) the probability of null precipitation was zero.

There are at least two alternative procedures in handling null amounts of precipitation apart from the method used in this study (Eq. 3). The first procedure is quite "naïve" and substitutes the null precipitation with a small amount of precipitation, for example $1 \mathrm{~mm}$. This substitution does not affect the distribution of precipitation and circumvent the problem. The second alternative procedure is to use the PoissonGamma distribution instead of using the Gamma distribution as proposed by Lana and Burgueno (2000).

The cumulative probability, $H(P)$, after its computation, is transformed to the standard normal random variable $z$ with 
Table 1. Weather classification by SPI values and corresponding event probabilities.

\begin{tabular}{ccc}
\hline SPI value & Category & Probability $(\%)$ \\
\hline 2.00 or more & Extremely wet & 2.3 \\
1.50 to 1.99 & Severely wet & 4.4 \\
1.00 to 1.49 & Moderately wet & 9.2 \\
-0.99 to 0.99 & Near normal & 68.2 \\
-1.49 to -1.00 & Moderately dry & 9.2 \\
-1.99 to -1.50 & Severely dry & 4.4 \\
-2 or less & Extremely dry & 2.3 \\
\hline
\end{tabular}

mean equal to zero and variance of one, which is the value of the SPI. Once standardized the strength of the anomaly is classified as set out in Table 1. This table also contains the corresponding probabilities of occurrence of each severity arising naturally from the Normal probability density function. Thus, at a given location for an individual month, moderate dry periods $(\mathrm{SPI} \leq-1)$ have an occurrence probability of $15.9 \%$, whereas extreme dry periods $(\mathrm{SPI} \leq-2)$ have an event probability of $2.3 \%$. Extreme values in the SPI will, by definition, occur with the same frequency at all locations.

In this study, the monthly gridded precipitation data were used for the estimation of the SPI for each grid cell for 1month, 3-month, 6-month, 9-month, and 12-month precipitation accumulations for each month of the period of analysis. The procedure, adopted in this study for the calculation of gridded SPI values, is called interpolate-calculate, because first the precipitation is spatially distributed and, then, the SPI time series are calculated in each grid. An alternative strategy would be to firstly calculate the SPI time series at each precipitation station and then interpolate the SPI values into grids. This strategy is called calculate-interpolate. Bechini et al. (2000) reported that the first procedure (i.e. interpolate-calculate procedure) should be followed, especially for non-linear models, paying considerable attention in the accurate interpolation of the initial parameters.

\subsection{Temporal and spatial analysis of droughts in Thessaly region}

The temporal and spatial characteristics of droughts in Thessaly region were assessed by analyzing the gridded SPI values. The computed gridded SPI values of various time scales and for the period of analysis (October 1960 to September 1993) were entered into a Geographical Information System (GIS) database. Firstly, the temporal variation of SPI was assessed using the regional representative of SPI, calculated from the time series of the mean areal precipitation of the Thessaly region. Analysis of the computed SPI time series revealed the most severe and extreme droughts occurred in the region. Then, the spatial characteristics of droughts during these severe dry periods were analyzed and visualized within the GIS. The spatial characteristics of droughts were further analyzed and the areas (or grids) affected by a speci- fied drought severity were estimated within GIS. Finally, performing frequency analysis the annual and monthly Drought Intensity or Drought Severity-Areal Extent-Frequency (SAF) curves were developed for the region. Two types of annual SAF curves were developed: a) the weighted cumulative SAF curves, and $b$ ) the average SAF curves.

The weighted annual cumulative SAF curves were developed according to the following procedure:

- For every year, the computed gridded monthly SPI values for various time scales were used,

- The annual weighted cumulative drought severity in each grid was estimated by multiplying the annual sum of SPI in monthly dry spells (negative SPI values) for a particular time scale by the probability of drought occurrence for each year,

- The probability of annual drought occurrence for each year and in each grid was estimated by dividing the number of months that have a negative SPI value for the particular time scale by 12 ,

- Obtain the drought severity associated with the areal extent using the distribution map produced in the GIS,

- Perform frequency analysis for each drought areal extent percentage to associate the drought severity with return periods, considering an adequate probability distribution,

- Develop the weighted annual cumulative SAF curves for the particular time scale and repeat the analysis for the next time scale.

This analysis resembles the analysis proposed for PDSI analysis by Kim and his associates (2002). With this analysis each drought event can be allotted evenly for a particular year, avoid intermittence, and the duration of dry spells within a particular year is implicitly taken into account.

The annual average SAF curves were developed according to the following procedure:

- For every year, the computed gridded monthly SPI values for various time scales were used,

- The annual average drought severity in each grid was estimated by dividing the annual sum of SPI in monthly dry spells (negative SPI values) for a particular time scale by 12 ,

- Obtain the drought severity associated with the areal extent using the distribution map produced in the GIS,

- Perform frequency analysis for each drought areal extent percentage to associate the drought severity with return periods, considering an adequate probability distribution,

- Develop the average annual SAF curves for the particular time scale and repeat the analysis for the next time scale. 

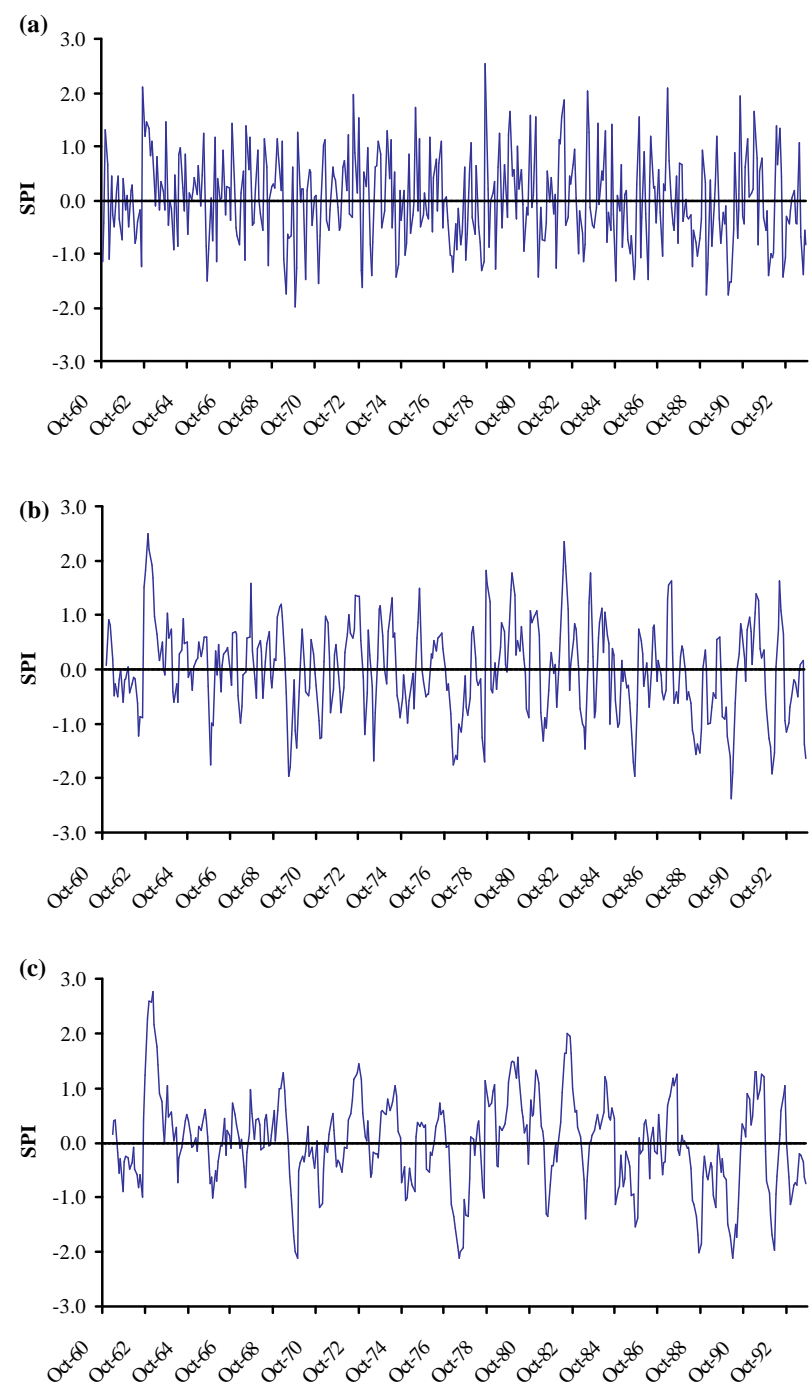

Fig. 4. Time series of average SPI values for Thessaly region for (a) 1-month, (b) 3-month, (c) 6-month, (d) 9-month and (e) 12-month time scales.

This analysis evaluates the annual drought severity without giving any consideration on the duration of the monthly dry spells. This means that an extreme drought event that lasts few months may have the same representation with a long lasting moderate dry spell. However, this analysis indicates, on average, how much drier is a particular year, and it could be used in conjunction with the previous weighted annual cumulative SAF curves to assess the impact of drought duration.

Apart from the two previous annual analyses, an analysis of monthly drought severity was performed for each month of the year and for various time scales, according to the following procedure:

- For every year, the computed gridded monthly SPI values for various time scales were used,

- Obtain the drought severity associated with the areal extent for a particular month of a particular year using the distribution map produced in the GIS,
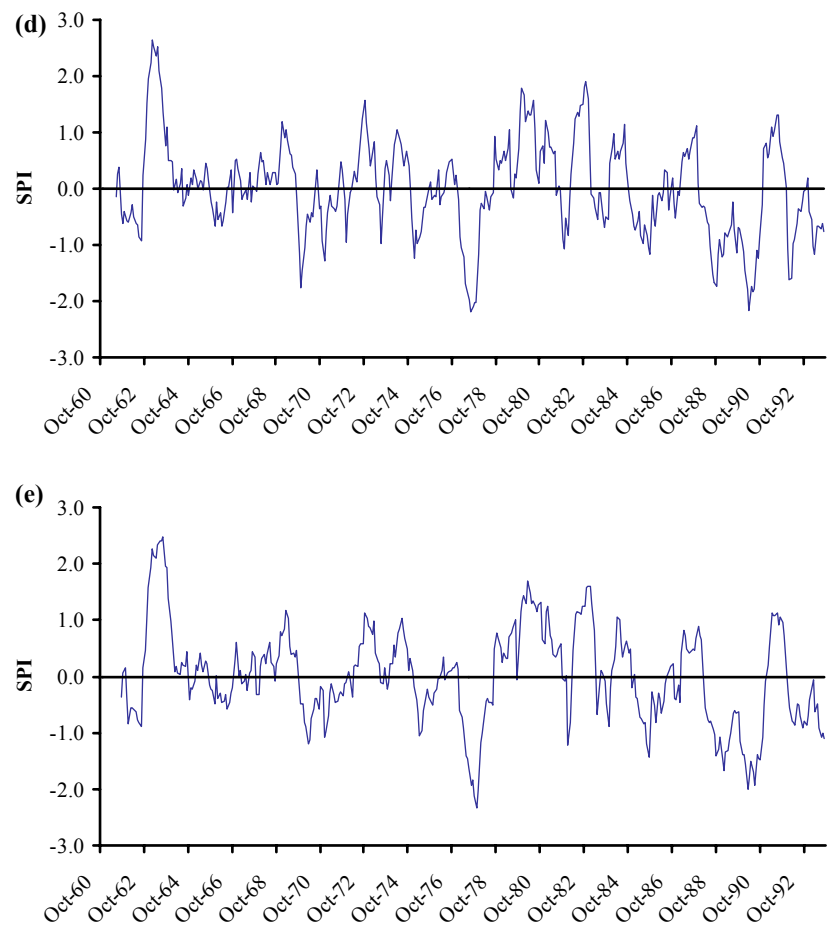

Fig. 4. Continued.

- Perform frequency analysis for each drought areal extent percentage to associate the drought severity with return periods, considering an adequate probability distribution,

- Develop the monthly SAF curves for the particular month and time scale and repeat the analysis for the next time scale.

This analysis could be used to evaluate the severity of observed consequent monthly dry spells and to predict the state of natural resources (vegetation, water resources, etc) and agriculture in prolonged dry spells.

The frequency analysis is commonly used in hydrology and meteorology to assess the return period of particular events. In this study, the drought severity or drought intensity has negative values. The negative values of drought severity were transformed to positive values to represent the extreme conditions and analyze the exceedance probability. Various theoretical probability distributions were statistically tested before fitting the observed drought severity. Specifically, the theoretical probability distributions tested for fitting the observed drought severity for the two annual analyses (weighted annual cumulative drought severity and average annual drought severity) and the monthly analyses (monthly drought severity) and for the various SPI time scales (1-month, 3-month, 6-month, 9-month, and 12month) were the Generalized Extreme Value (GEV), the Extreme Value I (EVI, Gumbel), Log-Normal-2 parameter, Log-Normal-3 parameter, Gamma, Log Pearson III, Generalized Pareto, Weibull distributions. In this study, the non- 
Table 2. Relative frequency of occurrence (\%) of annual minimum monthly SPI for various time scales using regional representative SPI.

\begin{tabular}{cccccc}
\hline Month & 1-month SPI & 3-month SPI & 6-month SPI & 9-month SPI & 12-month SPI \\
\hline January & 9.1 & 6.1 & 3.0 & 3.1 & 3.1 \\
February & 9.1 & 6.1 & 0.0 & 3.1 & 6.3 \\
March & 12.1 & 9.1 & 12.1 & 3.1 & 6.3 \\
April & 6.1 & 0.0 & 12.1 & 9.4 & 3.1 \\
May & 6.1 & 9.1 & 3.0 & 0.0 & 6.3 \\
June & 3.0 & 9.1 & 6.1 & 0.0 & 9.4 \\
July & 21.2 & 9.1 & 0.0 & 12.5 & 3.1 \\
August & 3.0 & 6.1 & 6.1 & 6.3 & 12.5 \\
September & 6.1 & 18.2 & 21.2 & 18.8 & 15.6 \\
October & 6.1 & 6.1 & 12.1 & 18.8 & 21.9 \\
November & 6.1 & 9.1 & 6.1 & 12.5 & 9.4 \\
December & 12.1 & 12.1 & 18.2 & 12.5 & 3.1 \\
\hline
\end{tabular}

parametric Kolmogorov-Smirnov (K-S) test and the parametric Chi-Square $\left(\chi^{2}\right)$ test were used for the selection of the most adequate probability distribution, although other statistical tests may be applied, such as L-moments, L-skewness, and L-kurtosis. Most of the theoretical probability distributions tested (i.e. GEV, EVI, Gamma, Log Person III and LogNormal-3 parameter) have passed the tests and they could have been used for drought frequency analysis. However, the EVI distribution was selected for the analysis because: 1) overall, it performed well for the annual and monthly analyses of drought severity and passed the two tests for all SPI time scales, 2) it is a two parameter probability distribution and its parameter values may be estimated with less uncertainty, especially for small samples, and 3) it is commonly used for drought analyses (Gottschalk and Perzyna, 1993; Lana and Burgueno, 1998; Henriques and Santos, 1999; Kim et al., 2002).

\section{Results}

\subsection{Temporal characteristics of droughts in Thessaly region}

The regional representative of SPI for the Thessaly region was calculated for multiple time scales, using the mean areal precipitation (Fig. 4). The time series of 1-month SPI (Fig. 4a) showed that the region experienced frequent moderate and severe droughts (i.e. SPI $<-1$ ) for all months of the year (Table 2). Analysis of the relative frequency of occurrence (Table 2) of the annual minimum monthly SPI showed that July is the month during which the 1-month SPI most frequently takes the annual minimum value and it is followed by December. Frequency analysis of the annual minimum monthly SPI, using the EVI probability distribution showed that the most extreme 1-month SPI (SPI=-1.98) occurred in October 1970 and had a return period of 22 years.

As the time scale increases, the monthly SPI time series were smoothed and the deviations from the long-term accumulated precipitation were assessed. The analysis of the 3- month SPI and 6-month SPI time series indicated that the record minimum SPI observed in March 1990 and April 1990, respectively (Figs. 4b and 4c). The drought severity for both time scales was evaluated as extreme (3-month $\mathrm{SPI}=-2.37$ and 6-month SPI=-2.12) and had return periods of 28 and 15 years, respectively. The annual minimum SPI values for the 3-month and 6-month time scale most frequently occur during September and December (Table 2).

The annual minimum 9-month and 12-month SPI values for the period of analysis were mainly observed in October and September (Table 2). Visual inspection of 9-month and 12-month SPI time series (Figs. 4d and 4e) indicated that droughts were quite frequent during the 1970s and 1980s. However, two distinct severe dry periods were revealed, considering only the annual minimum spatially averaged SPI value. The first period occurred during the hydrological year 1976-1977 and is characterized as an extreme drought event. The second period was the period from the hydrological year 1987-1988 to 1989-1990 and is characterized as a severe drought for the whole area of Thessaly. Especially, the annual precipitation of the year 1976-1977 is the smallest for the 33 years of analysis (October 1960 to September 1993). The drought occurred in 1976-1977 is the most severe drought ever experienced in Thessaly region. The annual minimum 9-month SPI for this drought event occurred in August 1977 (SPI=-2.19) and had a return period of 22 years, whereas the annual minimum 12-month SPI observed in November 1977 (SPI=-2.35) and had an estimated frequency of recurrence of 37 years.

The second drought event is a much more prolonged drought event than the drought event of 1976-1977 and lasted over three years (1987-1990), it is interrupted by the wet 1990-1991 hydrologic year and continued until the end of 1992-1993 hydrologic year. The minimum values of spatially averaged monthly SPI were observed during the hydrologic year 1989-1990 for the 9-month and 12-month time scales and it is characterized as a severe drought event. The minimum 9-month SPI was observed in April 1990 


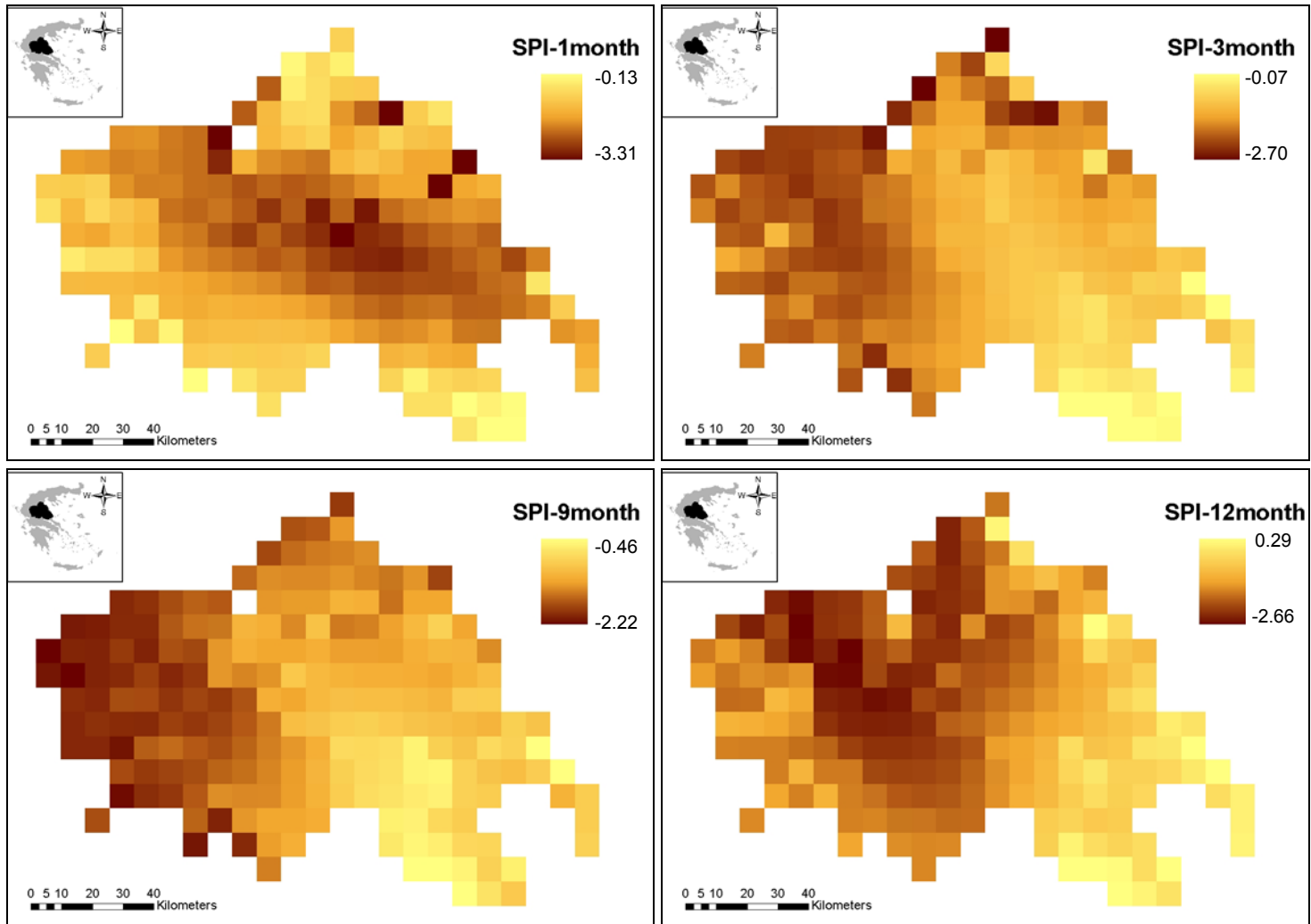

Fig. 5. Variation of SPI in February 1990 across Thessaly for various time scales.
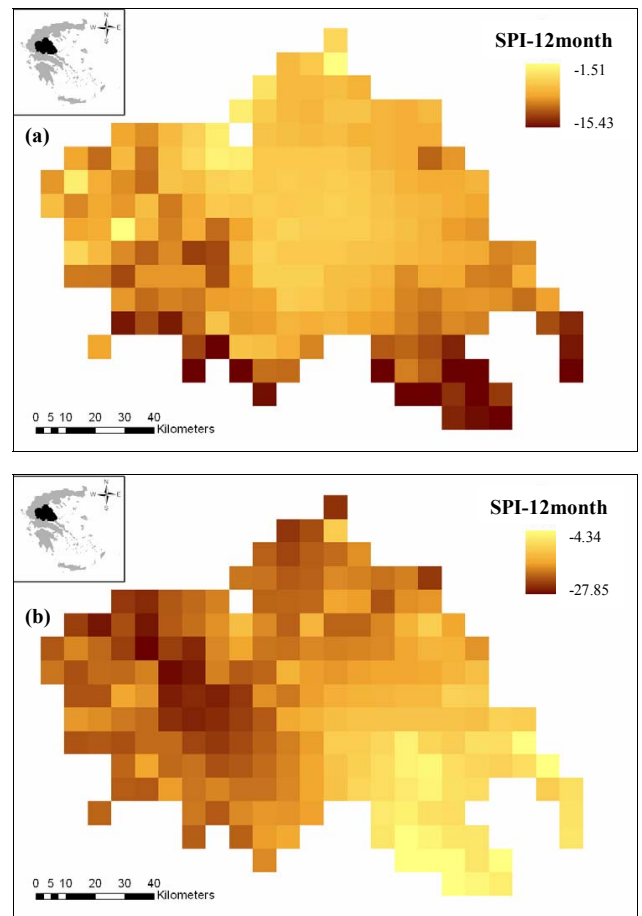

Fig. 6. Spatial variation of weighted annual cumulative 12-month SPI for (a) hydrologic year 1976-1977, and (b) hydrologic year 1989-1990.
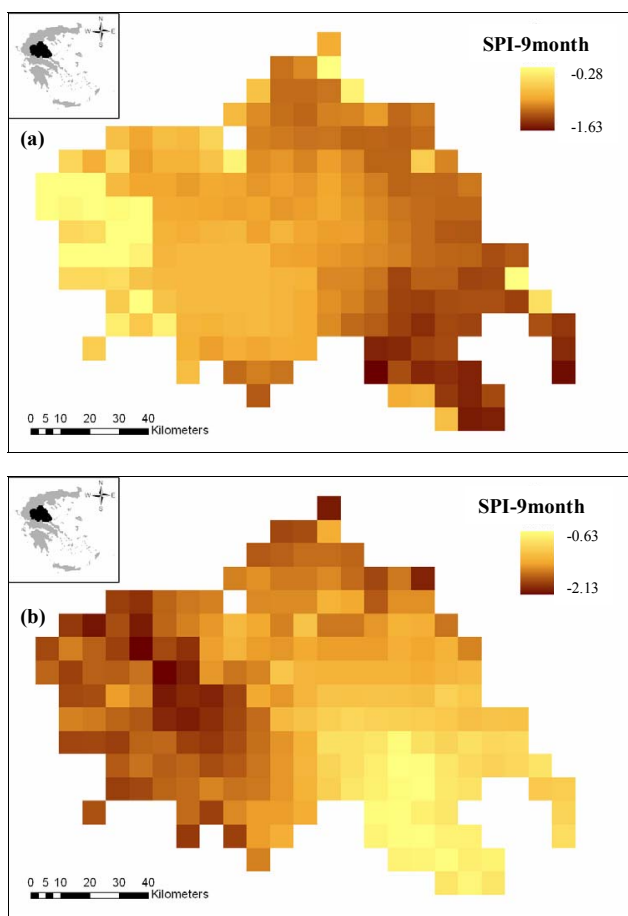

Fig. 7. Spatial variation of average annual 9-month SPI for (a) hydrologic year 1976-1977, and (b) hydrologic year 1989-1990. 

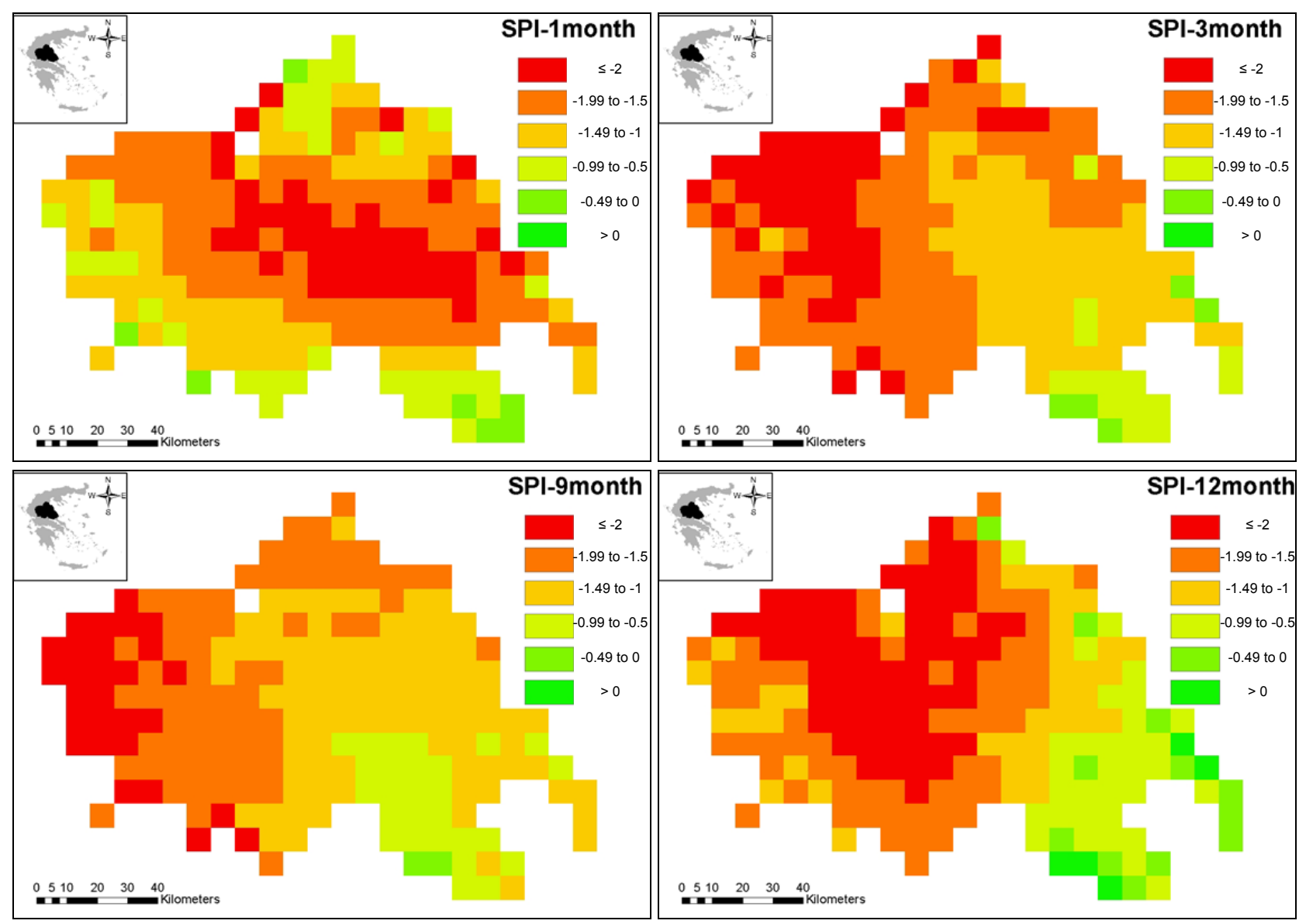

Fig. 8. Maps of areal extent for various time scales of SPI classes in February 1990.

(SPI=-2.16) and the minimum 12-month SPI was estimated for March 1990 (SPI=-2.00). This event had an estimated return period of 20 years for the 9-month time scale and of 18 years for the 12 -month time scale. This prolonged drought event caused exploding water demands and subsequent impacts in Thessaly region, Greece, and Eastern Mediterranean, in general.

\subsection{Spatial characteristics of droughts in Thessaly region}

Although the estimation of drought severity at a point or as regional representative gives useful information for water management, it is interesting and important to assess the drought over a specified region or basin. The regional drought analysis is useful for determining the spatial distribution and characteristics of drought, and evaluating the most affected areas for a specific drought event. In this study, the spatial analysis was performed using the gridded SPI values estimated for various time scales. Using the developed SPI database and the abilities of GIS, one can visualize the distribution of SPI values across the area of interest for various time scales. As an example, Fig. 5 shows the variation of SPI across Thessaly for February 1990 for time scales of 1month, 3-month, 9-month and 12-month. It should be noted that February of 1990 is the second driest February in record for the whole region and it is one of the months of the prolonged three year drought episode discussed earlier. The spatial distribution of drought for this particular month is quite different when the SPI was assessed at the various time scales (Fig. 5). Using the 1-month SPI, it seems that an area in the centre of the region and with direction north to southeast was the area affected the most by the drought. When larger time scales of SPI were used (e.g. 3-month and 9-month) the pattern changes and indicates that the most drought affected areas were the western and northern areas of the region. Finally, the spatial variation of the 12-month SPI shows that the most affected areas are the northern and central areas.

Using GIS and the estimated weighted annual cumulative SPI and the average annual SPI, the spatial distribution of a particular annual drought episode could be assessed. As an example, Figs. 6 and 7 show the spatial variation of weighted annual cumulative 12-month SPI and the average annual 9month SPI, respectively, for the first (1976-1977) and second (1989-1990) driest hydrological years in record. Figure 6 indicates that during the hydrological year 1976-1977, the weighted annual cumulative drought intensity was larger for the southern and some western areas of the region, whereas during the 1989-1990 hydrological year the most drought affected areas were lie in the northern and western part of the 

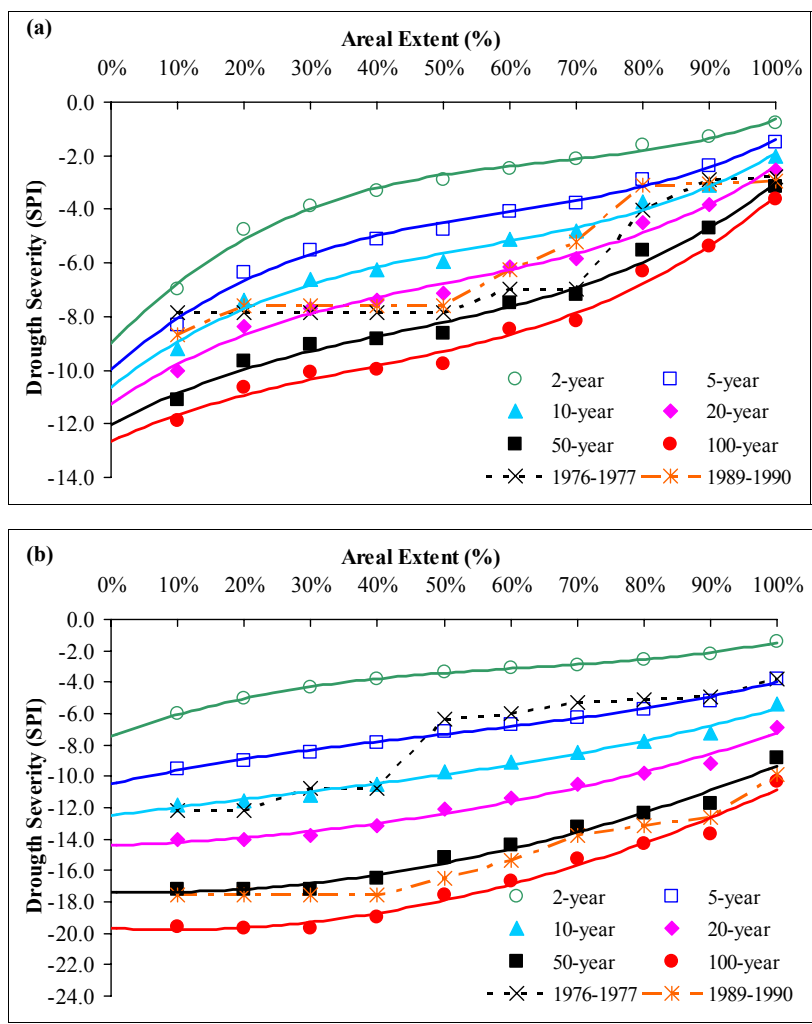

Fig. 9. Severity - Areal Extent - Frequency curves of the weighted annual cumulative drought severity for (a) 1-month SPI, and (b) 12-month SPI.

region. Similar spatial pattern was observed using the average annual SPI (Fig. 7) for the 1989-1990 hydrological year. For the 1976-1977 hydrological year, this analysis indicates that not only the southern areas of the region but also the eastern part of Thessaly experienced severe drought.

The above analyses show that, when accounting the duration and the intensity of drought for consecutive dry months, the drought of the year 1989-1990 was more severe than the drought of 1976-1977. For example, the weighted annual cumulative 12-month SPI for 1989-1990 and 19761977 (Fig. 6) ranges from -4.54 to -27.85 , and -1.51 to -15.43 , respectively. Similarly, the analysis for the average annual 9-month SPI (Fig. 7) indicates that the SPI values for 1989-1990 range from -0.63 to -2.13 whereas, the SPI for the latter year ranges from -0.28 to -1.36 . These results demonstrate the importance of drought duration in the estimation of drought severity.

\subsection{Drought Severity-Areal Extent-Frequency curves for Thessaly region}

A method to assess the spatial characteristics and the frequency over an area is the Drought Severity-Areal ExtentFrequency (SAF) curves. In this study, the SAF curves were developed for Thessaly region using the GIS capabilities and the spatial SPI database. The SAF curves were developed for the weighted annual cumulative drought severity, the average
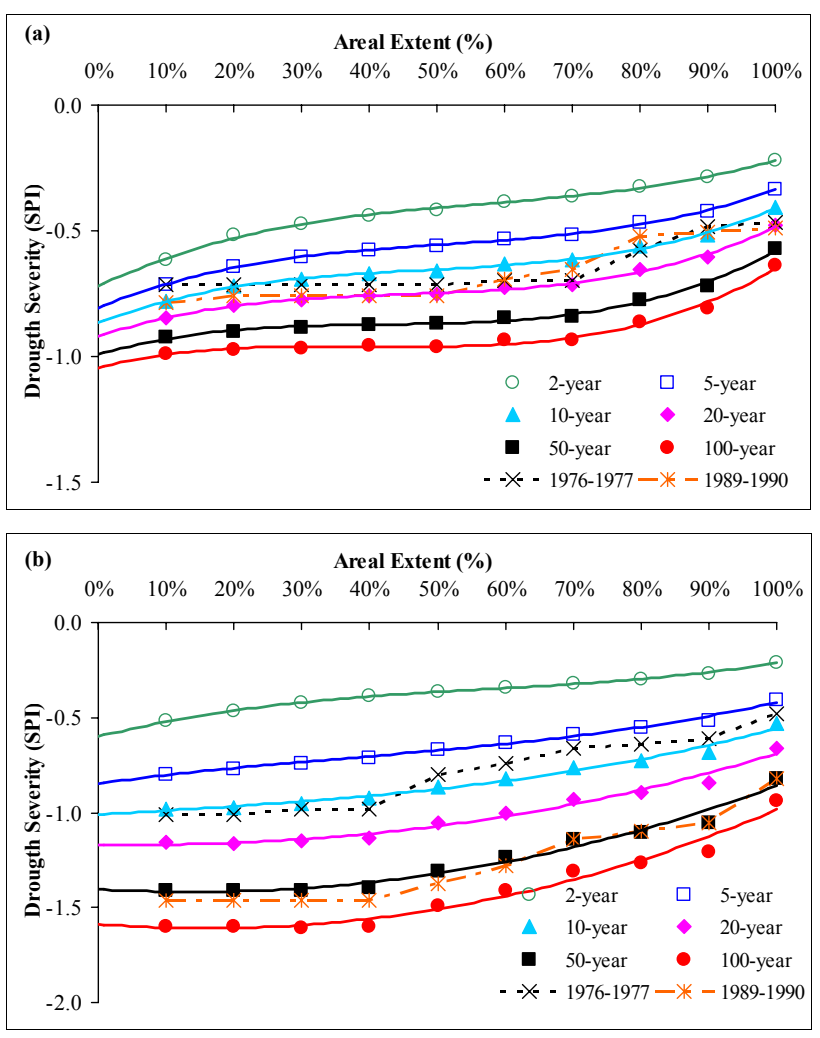

Fig. 10. Severity - Areal Extent - Frequency curves of the average annual drought severity for (a) 1-month SPI, and (b) 12-month SPI.

annual drought severity, and the monthly drought severity for multiple time scales of SPI. The procedures for estimating the SAF curves have been outlined earlier in the paper. The percentage of the areal extent associated with a specified drought severity (or negative SPI value) was obtained by applying multiple queries in the GIS SPI database and analyzing the results. Figure 8 shows, as an example such a multiple query for February 1990. Since, it is not feasible, due to paper length limitations, to show all the developed SAF curves only indicative SAF curves will be presented.

Followed the steps of analysis previously presented, the SAF curves of the weighted annual cumulative drought severity were developed. Figure 9 shows two of the five SAF curves that were developed for 1-month and 12-month SPI. This figure indicates that although the drought intensity of the 1976-1977 event is more severe that the respective event of 1987-1990 in 1-month time scale for most of the areal extent of Thessaly (Fig. 9a). However, in 12-month time scale, the pattern reverses and the latter event reaches a return period for more than 80 years for most of the area of Thessaly, whereas the first event has a 10-year return period for less than $40 \%$ of the region (Fig. 9b). The reason for this difference is the larger duration of the 1987-1990 drought compared to the duration of the 1976-1977 event.

Similar results have been found in the analysis of the average annual SAF curves (Fig. 10). These results indicate that the 1987-1990 drought event was much more prolonged with 

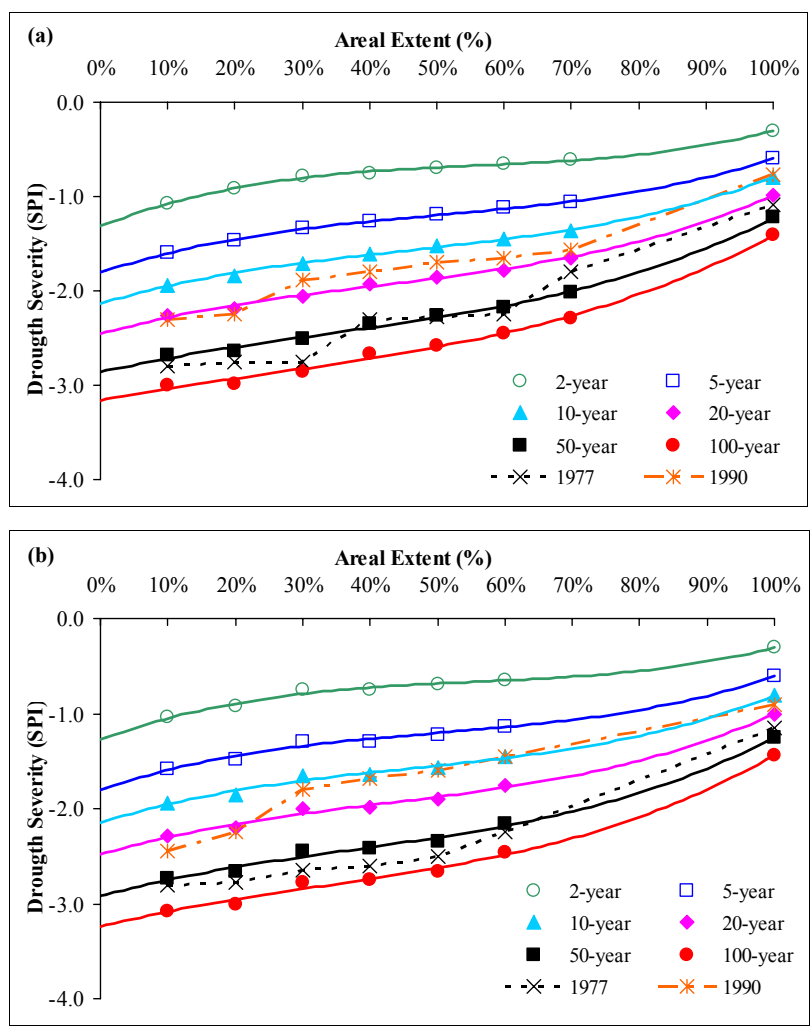

Fig. 11. Severity - Areal Extent - Frequency curves of 12-month SPI monthly drought severity for (a) October, and (b) August.

continuous negative monthly values of SPI and had a negative impact on much larger area than the 1976-1977 event. Thus, the drought occurred in the 1989-1990 hydrological year was more severe than the 1976-1977 drought considering the duration and areal extent contrarily to the results of the analysis of the spatially averaged drought severity presented before.

An example of the monthly SAF curves is presented in Fig. 11 for October (Fig. 11a) and August (Fig. 11b) for 12month time scale. On this figure, the SAF curves for October 1977, October 1990, August 1977 and August 1990 were been plotted indicating that the drought intensity in October 1977 and August 1977 was more severe than the drought intensity in the respective months of 1990. Especially, the drought severity in August 1977 reached a return period of 80 years for more than $50 \%$ of Thessaly region (Fig. 11b).

\section{Conclusions}

This study was focused on presenting a framework of methodologies for the analysis of the temporal and spatial characteristics and frequency of droughts in Thessaly region, Greece. The SPI computed at various time scales was used as an indicator of drought severity. The SPI was computed using spatially distributed or gridded precipitation and a database of computed SPI values was developed. Using this database, three analyses were performed: 1) an analysis of the temporal variation and frequency of droughts using the spatially averaged SPI over Thessaly as a regional representative, 2) an analysis of the spatial variation of droughts with the help of GIS capabilities, and 3) a regional frequency analysis that lead to the development of Drought Severity Areal Extent - Frequency curves. The last two analyses were performed for each month of the year and for annual drought severity. The annual drought severity was assessed by using the weighted annual cumulative negative SPI and the average annual negative SPI.

The temporal and spatial drought analyses indicated that Thessaly experience quite frequent moderate and severe droughts on monthly basis. The region has experienced prolonged and severe droughts during the periods of 1976-1977 and 1987-1990. In particular, the persistent and prolonged drought of 1987-1990 seriously affected urban water supply and agricultural irrigation. The spatial variation of droughts during the two periods was quite different. For the 1976 1977 drought, the most affected areas were the southern and coastal areas of Thessaly, whereas the western and northern areas of Thessaly were mostly affected during the prolonged drought during the period 1989-1990. This drought, although was less severe than the 1976-1977 event, as the frequency analysis of the annual minimum spatially averaged SPI showed, had a larger spatial coverage and longer duration, and affected the headwater areas of Pinios River and its tributaries. As a result, this meteorological drought period was associated with hydrological and water resources drought resulted in significant decrease in the flows of Pinios River. It has been shown that the drought occurred in the late 1980s was associated with a return period of more than 80 years with a large areal extent. The identification of the temporal and spatial characteristics of droughts in Thessaly will be useful for the development of a drought preparedness plan in the region.

The future research steps will be to investigate the interconnectivity of meteorological drought with hydrological and water resources drought, to evaluate the forecasting potential of droughts using remote sensing indices (e.g. NDVI) and meteorological data, and to predict the spatiotemporal distribution pattern of SPI with a generalized global interpolation model.

Acknowledgements. The authors would like to thank N. B. Guttman and an anonymous reviewer for their helpful comments, which improved the quality of the final manuscript. The authors would also like to acknowledge the editor, U. Ulbrich, for the rigorous and timely handling of the reviewing process of the paper.

Edited by: U. Ulbrich

Reviewed by: N. B. Guttman and another referee 


\section{References}

American Meteorological Society, (AMS): Statement on meteorological drought, Bull. Am. Meteorol. Soc., 85, 771-773, 2004.

Bechini, L., Ducco, G., Donatelli, M., and Stein, A.: Modelling interpolation and stochastic simulation in space and time of global solar radiation, Agr. Ecosyst. Environ., 81, 29-42, 2000.

Bhalme, H. N. and Mooley, D. A.: Large scale droughts/floods and monsoon circulation, Mon. Weath. Rev., 108, 1197-1211, 1980.

Bordi, I. and Sutera, A.: Fifty years of precipitation: Some spatially remote teleconnections, Water Resour. Manag., 15, 247280, 2001.

Bordi, I., Frigio, S., Parenti, P., Speranza, A., and Sutera, A.: The analysis of the Standardized Precipitation Index in the Mediterranean area: regional patterns, Annali di Geofisica, 44, 5-6, 979993, 2001

Chiew, F. H. A., Piechota, T. C., Dracup, J. A., and McMahon, T. A.: El Niño Southern Oscillation and Australian rainfall, streamflow and drought: Links and potential for forecasting, J. Hydrol., 204, 1-4, 138-149, 1998.

Dracup, J. A., Lee, K. S., and Paulson, Jr., E. G.: On the definition of droughts, Water Resour. Res., 16, 2, 297-302, 1980.

Gibbs, W. J. and Maher, J. V.: Rainfall deciles as drought indicators, Australian Bureau of Meteorology Bulletin, No. 48, Commonwealth of Australia, Melbourne, 37, 1967.

Gonzalez, J. and Valdes, J. B.: The mean frequency of recurrence of in-time-multidimensional events for drought analyses, Nat. Haz. Earth Sys. Sci., 4, 17-28, 2004,

\section{SRef-ID: 1684-9981/nhess/2004-4-17.}

Gottschalk, L. and Perzyna, G.: Low flow distribution along a river, in: Extreme Hydrological Events: Precipitation, Floods and Droughts, edited by Kundzewicz, Z. W., Rosbjerg, D., Simonovic, S. P., and Takeuchi, K., IAHS, Publ. No. 213, 33-41, 1993.

Guttman, N. B.: Accepting the standardized precipitation index: A calculation algorithm, J. Am. Water Resour. Assoc., 35, 2, 311$322,1999$.

Guttman, N. B.: Comparing the Palmer Drought Index and the Standardized Precipitation Index, J. Am. Water Resour. Assoc., 34, 1, 113-121, 1998.

Hayes, M. J., Svoboda, M. D., Wilhite, D. A., and Vanyarkho, O. V.: Monitoring the 1996 drought using the standardized precipitation index, Bull. Am. Meteorol. Soc., 80, 2, 429-438, 1999.

Henriques, A. G. and Santos, M. J. J.: Regional drought distribution model, Phys. Chem. Earth (B), 24, 1-2, 19-22, 1999.

Hoerling, M., and Kumar, A.: The perfect ocean for drought, Science, 299, 691-694, 2003.

Jones, P. D. and Hulme, M.: Calculating regional climatic time series for temperature and precipitation: Methods and illustrations, Int. J. Climatol., 16, 361-377, 1996.

Keyantash, J. and Dracup, J. A.: The quantification of drought: An evaluation of drought indices, Bull. Am. Meteorol. Soc., 83, 8, 1167-1180, 2002.

Kim, T. W., Valdes, J. B., and Aparicio, J.: Frequency and spatial characteristics of droughts in the Conchos River Basin, Mexico, Water Int., 27, 2, 420-430, 2002.

Lana, X. and Burgueno, A.: Spatial and temporal characterization of annual extreme droughts in Catalonia (Northern Spain), Int. J. Climatol., 18, 93-110, 1998.

Lana, X. and Burgueno, A.: Some statistical characteristics of monthly and annual pluviometric irregularity for the Spanish Mediterranean coast, Theor. Appl. Climatol., 65, 1-2, 79-97, 2000.
Lana, X., Serra, C., and Burgueno, A.: Patterns of monthly rainfall shortage and excess in terms of the standardized precipitation index for Catalonia (NE Spain), Int. J. Climatol., 21, 13, 16691691, 2001.

Lloyd-Hughes, B. and Saunders, M. A.: A drought climatology for Europe, Int. J. Climatol., 22, 1571-1592, 2002.

Loukas, A. and Mylopoulos, N.: Implications of hydro-technical projects development on water balance of Pinios river basin, Thessaly, Electronic Proceedings of the 7th International Conference of Protection and Restoration of the Environment, 28 June - 2 July 2004, Mykonos, Greece, 8 pp., 2004.

Loukas, A., Vasiliades, L., and Dalezios, N. R.: Intercomparison of meteorological drought indices for drought assessment and monitoring in Greece". Proceedings of the 8th International Conference on Environmental Science and Technology, 8-10 September 2003, Lemnos, Greece, 484-491, 2003.

Loukas, A., Vasiliades, L., and Dalezios, N. R.: Evaluation of precipitation spatial interpolation methods in Pinios River basin, Greece”, 1st EGU General Assembly, 25-30 April 2004, Nice, France, Geophysical Research Abstracts, 6, 2004.

McKee, T. B., Doesken, N. J., and Kleist, J.: Drought monitoring with multiple time scales, Preprints, 9th Conference on Applied Climatology, Dallas, TX, Amer. Meteor. Soc., 233-236, 1995.

McKee, T. B., Doesken, N. J., and Kleist, J.: The relationship of drought frequency and duration to time scales, Preprints, 8th Conference on Applied Climatology, Anaheim, CA, Amer. Meteor. Soc., 179-184, 1993.

Naoum, S. and Tsanis, I. K.: Temporal and spatial variation of annual rainfall on the island of Crete, Greece, Hydrol. Process., 17, 10, 1899-1922, 2003.

Palmer, W. C.: Meteorological drought. Research Paper No. 45, U.S. Weather Bureau, Washington, D.C., 58 pp., 1965.

Piechota, T. C. and Dracup, J. A.: Drought and regional hydrologic variation in the US: associations with the El Niño-Southern Oscillation, Water Resour. Res., 32, 5, 1359-1373, 1996.

Quiring, S. M., and Papakryiakou, T. N.: An evaluation of agricultural drought indices for the Canadian prairies, Agr. Forest Meteorol., 118, 49-62, 2003.

Redmond, K. T.: Integrated climate monitoring for drought detection, in Drought: A Global Assessment, edited by Wilhite, D. A., Routledge, 145-158, 2000.

Sims, A. P., Niyogi, D. S., and Raman, S.: Adopting drought indices for estimating soil moisture: A North Carolina case study, Geophys. Res. Lett., 29, 8, 1183, doi:10.1029/2001GL013343, 2002.

Tadesse, T., Wilhite, D. A., Harms, S. K., Hayes, M. J., and Goddard, S.: Drought monitoring using data mining techniques: A case study for Nebraska, USA, Natural Hazards, 33, 1-21, 2004.

Tate, E. L. and Gustard, A.: Drought definition: A hydrological perspective, in: Drought and Drought Mitigation in Europe, edited by Voght, J. V. and Somma, F., Kluwer Academic Publishers, Dordrecht, 23-48, 2000.

Tsakiris, G. and Vangelis, H.: Towards a drought watch system based on spatial SPI, Water Resour. Manag., 18, 1-12, 2004.

van Rooy, M. P.: A rainfall anomaly index independent of time and space, Notos, 14, 43-48, 1965.

Wilhite, D. A. and Glantz, M. H.: Understanding the drought phenomenon: The role of definitions, Water Inter., 10, 2, 111-120, 1985.

Wilhite, D. A.: Drought as a natural hazard: Concepts and definitions, in Drought: A Global Assessment, edited by Wilhite, D. A., Routledge, 3-18, 2000. 